Г. В. Худов ${ }^{1}$, О. М. Маковейчук ${ }^{2}$, І. А. Хижняк ${ }^{1}$ Ю. С. Соломоненко ${ }^{1}$, І. Ю. Юзова ${ }^{1}$

${ }^{1}$ Харківський національний університет Повітряних Сил імені Івана Кожедуба, Харків, Україна

${ }^{2}$ Харківський національний університет радіоелектроніки, Харків, Україна

\title{
МЕТОД ВИДІЛЕННЯ ОБ'ЄКТІВ МІСЬКОЇ ЗАБУДОВИ НА ЗОБРАЖЕННЯХ БОРТОВИХ СИСТЕМ ОПТИКО-ЕЛЕКТРОННОГО СПОСТЕРЕЖЕННЯ З ВИКОРИСТАННЯМ ПЕРЕТВОРЕННЯ ХАФА
}

\begin{abstract}
Предметом вивчення в статті є метод виділення об'єктів міської забудови на зображеннях бортових систем оптико-електронного спостереження. Метою $є$ розробка методу виділення об'єктів міської забудови на зображеннях бортових систем оптико-електронного спостереження. Завдання: обгрунтування необхідності виділення об'єктів міської забудови на зображеннях бортових систем оптико-електронного спостереження; викладення сутності методу виділення об'єктів міської забудови на зображеннях бортових систем оптико-електронного спостереження; візуальна оцінка якості виділення об'єктів міської забудови на зображеннях бортових систем оптико-електронного спостереження. Використовуваними методами $€$ : методи теорії імовірності, математичної статистики, методи оптимізації, математичного моделювання та цифрової обробки зображень. Отримані такі результати. Встановлено, що актуальним $є$ питання виділення на зображеннях бортових систем оптико-електронного спостереження географічного ландшафту, будівель, культурних центрів і критичних елементів інфраструктури, типу підприємств, транспортних систем та інших важливих забудов. Встановлено, що об'єкти міської забудови (мости, дороги, будинки тощо) є досить контрастними і містять багато прямих ліній. Виділення об'єктів міської забудови розглядається як двоетапний метод, а саме, застосування деякого детектора границь та застосування безпосередньо перетворення Хафа. На першому етапі проводиться виділення границь, на другому - виділення прямих ліній. У якості детектору границь запропоновано використання детектору границь Канні. Висновки. Встановлено, що візуальна якість дозволяє виділити об'єкти міської забудови на обробленому зображенні, а запропонований метод може бути використано для знаходження об'єктів міської забудови. Напрямком подальших досліджень $є$ використання багатомасштабного методу обробки зображень.
\end{abstract}

Ключ юв і слов а : об'єкти міської забудови, оптико-електронне зображення, бортова система спостереження, перетворення Хафа, детектор границь Канні, візуальна оцінка якості, кольоровий простір.

\section{Вступ}

Постановка проблеми у загальному вигляді. Демографічні тенденції у світі призводять до того, що у подальшому урбанізація міст продовжиться, та, на жаль, у майбутньому все частіше військові операції усіх типів будуть проходити в умовах населених пунктів.

Міське середовище складне й різноманітне. Воно включає в себе як складне архітектурне середовище столиці в межах добре розвиненої інфраструктури, так і міські нетрі з високою і малої щільністю населення та 3 дуже бідною інфраструктурою. Сюди включаються міста й мегаполіси, які можуть самі по собі містити комерційні, індустріальні та житлові райони, а так само численні комунікації та енергетичні об'єкти. При цьому, комерційні, індустріальні, адміністративні і житлові райони потребують індивідуального аналізу. Тому бойові дії у місті різко відрізняються від дій в польових умовах.

Аналіз бойових дій та конфліктів останніх років показав, що успішним діям військ в містах багато в чому сприяла вміло організована і ефективно проведена розвідка та спостереження [1-6]. Детальне вивчення великих міст або окремих їх районів проводиться по великомасштабним планам, топографічним картам та даним повітряної та космічної розвідки та спостереження [2, 3]. Однак слід мати на увазі, що ряд важливих об'єктів, особливо військового характеру, на плані не вказано. Виявити такі об'єкти можна тільки 3 використанням повітряної та космічної розвідки.
Таким чином, основна вимога до розуміння особливостей поля бою включає оцінку географічного ландшафту, будівель, культурних центрів і критичних елементів інфраструктури, типу підприємств, транспортних систем та інших важливих забудов [1-3].

Мета статті - розробка методу виділення об'єктів міської забудови на зображеннях бортових систем оптико-електронного спостереження 3 використанням перетворення Хафа.

Аналіз останніх досліджень і публікацій. На сьогодні існує багато методів пошуку аналітично заданих примітивів [4-8]. Одним 3 найбільш ефективних методів пошуку аналітично заданих примітивів $\epsilon$ на сьогодні група методів, заснованих на ідеї перетворення Хафа. Ця ідея може бути модифікована для роботи з реальними даними на зображеннях, коли потрібно знайти той чи інший геометричний примітив, заданий аналітичним рівнянням, і при цьому на зображенні є не дві і не три, а значна кількість голосуючих контурних або особливих точок $[9,10]$. Класичне перетворення Хафа було спочатку розроблено для виділення на бінарному зображенні не кіл, а прямих ліній. Воно грунтується на використанні простору параметрів, в якому і проводиться пошук прямих [9].

\section{Основна частина}

Об'єкти міської забудови (мости, дороги, будинки тощо) є досить контрастними і містять багато прямих ліній. Отже, якщо для кожного каналу кольорового простору представлення кольорового 
зображення (наприклад, RGB) за допомогою деякого детектора знайти границі, то за допомогою перетворення Хафа в кожному каналі можна виділити прямі лінії. Якщо лінії об’єкта знаходяться в усіх трьох каналах RGB одночасно, то це є ознакою штучного походження об'єкта. Якщо тільки в одному каналі об'єкт має природне походження (наприклад, річка), якщо в двох каналах - класифікація ускладнена (це може бути, наприклад, польова дорога).

Отже, виділення об'єктів міської забудови будемо розглядати як двоетапний метод, а саме, застосування деякого детектора границь та застосування безпосередньо перетворення Хафа. На першому етапі проводиться виділення границь, на другому - виділення прямих ліній.

В статті у якості детектора границь будемо застосовувати детектор границь Канні. Етапи методу Канні наступні [5]:

1. Заладжування. Проводиться 3 метою зменшення впливу шумів на визначення границь, для чого використовується фільтр Гауса:

$$
f(x, y)=\frac{1}{2 \pi \sigma} e^{\left(-\frac{x^{2}+y^{2}}{2 \sigma^{2}}\right)},
$$

де $(\mathrm{x}, \mathrm{y})$ - координати пікселя на зображенні;

$\mathrm{f}(\mathrm{x}, \mathrm{y})$ - яскравість зображення;

$\sigma-$ параметр розмиття.

Значення параметра розмиття необхідно обрати таким, що забезпечує найбільше придушення шуму. Більше значення параметра використовується для виділення крупних границь, менше - для виділення маленьких деталей.

2. Пошук градієнту. Для визначення градієнту на зображенні після фільтру Гауса (1) будемо використовувати оператор Собеля, схема просторової фільтрації з використанням якого наведена на рис. 1.

Основою перетворення Собеля є припущення, що функція розриву яскравості на гранях становиться значно більше.

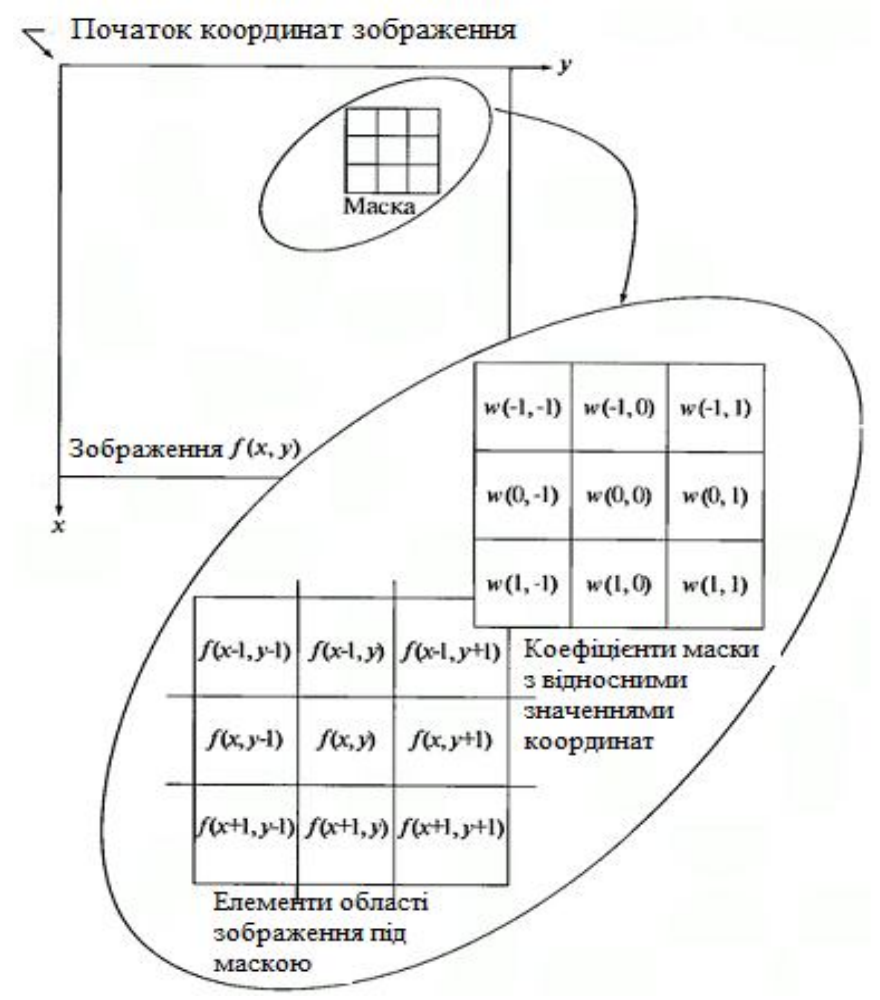

Рис. 1. Схема просторової фільтрації з використанням оператору Собеля

3 цього припущення можна зробити висновок, що для знаходження граней достатньо здійснити диференціювання функції яскравості $f(x, y)$ :

$$
\begin{aligned}
& \frac{\partial f(x, y)}{\partial x}=\Delta x=\frac{f(x+d x, y)-f(x, y)}{d x} \\
& \frac{\partial f(x, y)}{\partial y}=\Delta y=\frac{f(x, y+d y)-f(x, y)}{d y} .
\end{aligned}
$$

B дискретних зображеннях $\mathrm{dx}$ та $\mathrm{dy}$ можна вимірювати в кількості пікселів між двома точками 3 використанням таких виразів:

$$
\begin{aligned}
& \Delta x=f(i+1, j)-f(i, j), \\
& \Delta y=f(i, j+1)-f(i, j) .
\end{aligned}
$$

Вираз для визначення величини градієнту G можна записати таким чином:

$$
\mathrm{G}=\sqrt{(\Delta \mathrm{x})^{2}+(\Delta \mathrm{y})^{2}},
$$

а напрямок $\theta$ :

$$
\theta=\arctan \left(\frac{\Delta \mathrm{y}}{\Delta \mathrm{x}}\right)
$$


У виразах (6), (7) оцінка градієнту проводиться 3 використанням масок $(2 \times 2)$ :

$$
\begin{aligned}
& \Delta \mathrm{x}=\left(\begin{array}{cc}
-1 & 1 \\
0 & 0
\end{array}\right), \\
& \Delta \mathrm{y}=\left(\begin{array}{cc}
-1 & 0 \\
1 & 0
\end{array}\right) .
\end{aligned}
$$

Основний недолік використання масок (8) та (9) - це велика кількість помилок з причини наявності шуму. Крім того, використання масок парного порядку не дає можливості проводити оцінку на основі пікселя, що розташований по центру маски. Тому, будемо використовувати оператор Собеля 3 такими масками:

$$
\begin{aligned}
\mathrm{K}_{\mathrm{G}_{\mathrm{X}}} & =\left(\begin{array}{ccc}
-1 & 0 & 1 \\
-2 & 0 & 2 \\
-1 & 0 & 1
\end{array}\right), \\
\mathrm{K}_{\mathrm{G}_{\mathrm{y}}} & =\left(\begin{array}{ccc}
1 & 2 & 1 \\
0 & 0 & 0 \\
-1 & -2 & -1
\end{array}\right) .
\end{aligned}
$$

3 аналізу виразів (10), (11) (у порівнянні з (8), (9)) видно використання коефіцієнту 2 для середніх елементів. Збільшене значення коефіцієнту використовується для зменшення ефекту згладжування за рахунок надання більшої ваги середнім точкам. Значення та напрямок величини градієнту $G$ приймають вид (12), (13), відповідно:

$$
\begin{gathered}
G=\sqrt{G_{x}^{2}+G_{y}^{2}}, \\
\theta=\arctan \left(\frac{\left|G_{x}\right|}{\left|G_{y}\right|}\right) .
\end{gathered}
$$

Після використання оператора Собеля інтенсивність кожного пікселя вихідного зображення дорівнює градієнту вектора яскравості.

3. Придушення хибних максимумів. Мета цього етапу - перетворити "розмиті" границі в "чіткі". Це досягається збереженням локальних максимумів та видаленням всього іншого. Для кожного пікселя виконуються такі дії:

- напрямок градієнту округляється до найближчого значення, що кратне $45^{\circ}$ (рис. 2 , а);

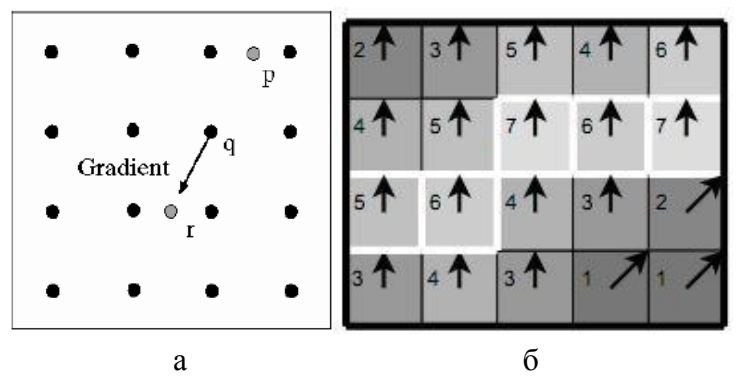

Рис. 2. Пошук локальних максимумів:

$\mathrm{a}$ - (максимуми р та $\mathrm{r}$ інтерполюються (видаляються)); б - принцип придушення хибних максимумів
- якщо у поточній точці досягається локальний максимум у напрямку градієнту, то вона є частиною границі;

- у противному випадку точка видаляється (рис. 2, б).

Принцип придушення проілюстрований на рис. 2, б. Всі пікселі на рис. 2, б мають орієнтацію вверх, тому значення градієнту в цих точках буде порівняно $з$ нижче та вище розташованими пікселями. Пікселі, що обведені білим кольором на рис. 2, б, залишаться у вихідному зображенні, інші - будуть придушені.

\section{Сутність:}

4. Подвійна порогова фільтрація (рис. 3).

кожен піксель, що перевищує верхній поріг, відмічається як "сильний",

кожен піксель, що попадає між двома порогами, - "слабкий" (яскравість таких пікселів приймає фіксоване середнє значення та буде уточнюватися на наступному етапі),

пікселі, що менше нижнього порогу - видаляються.

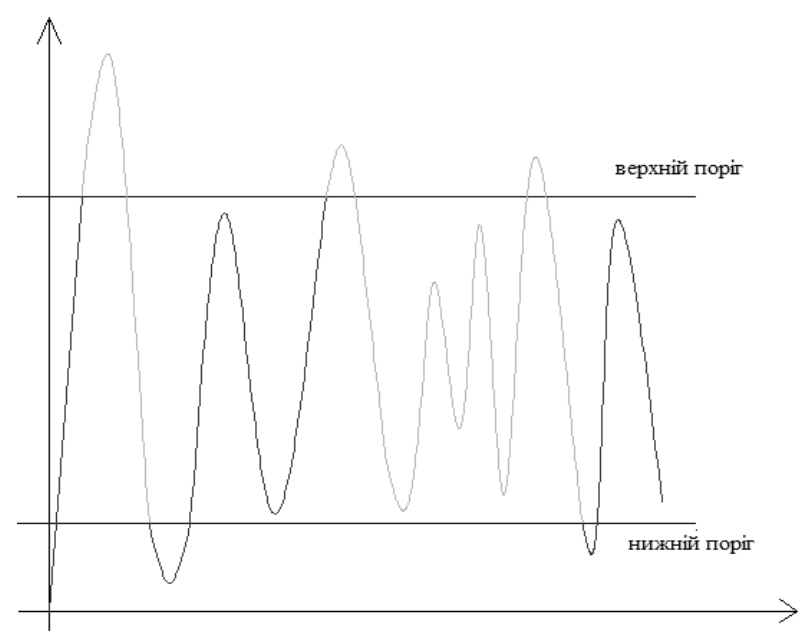

Рис. 3. Використання двох порогів в методі Канні

Використання подвійного порогу дозволяє зменшити вплив шуму (за рахунок верхнього порогу) та не втратити "хвости" (за рахунок нижнього порогу).

5. Трасування області невизначеності. Задача зводиться до виділення груп пікселів, що отримали на попередньому етапі проміжне значення, та віднесенню їх до границі (якщо вони з'єднанні з однією 3 встановлених границь) або їх придушенню (в противному випадку).

У якості вихідного будемо розглядати зображення, що отримане 3 бортової системи оптикоелектронного спостереження Ikonos (рис. 4) [4].

Результат застосування до вихідного зображення детектора границь Канні наведено на рис. 5. Обробка проводилася окремо для кожного каналу кольорового простору RGB вихідного зображення (рис. 4).

На рис. 6 наведено результат застосування перетворення Хафа до зображення (рис. 5). Обробка проводилася окремо для кожного каналу кольорового простору RGB зображення (рис. 5). 


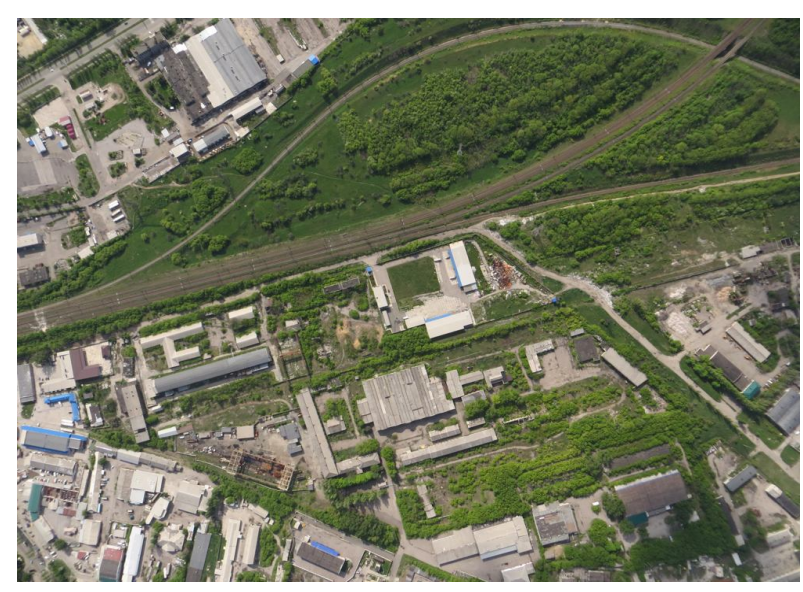

Рис. 4. Вихідне зображення

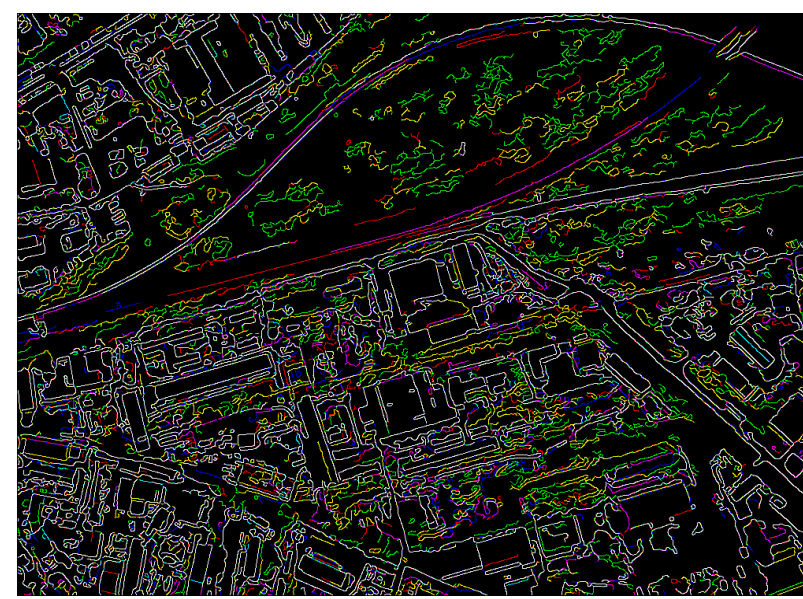

Рис. 5. Результат застосування до вихідного зображення (рис. 4) детектора границь Канні

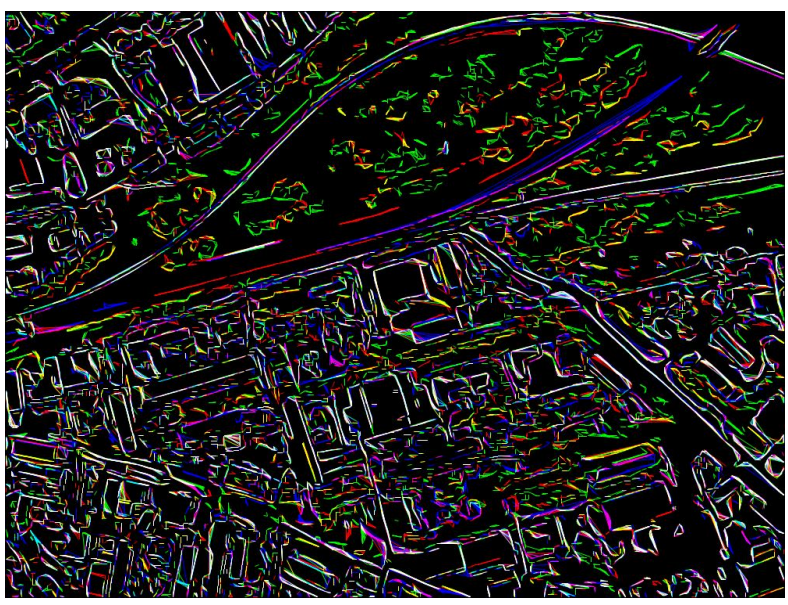

Рис. 6. Результат застосування перетворення Хафа до зображення (рис. 5)
На рис. 7 наведено результат накладення рис. 6 на вихідне зображення (рис. 4) 3 метою виділення об’єктів міської забудови. Результати такого виділення наведені на рис. 8. На рис. 8 наведені виділені об'єкти міської забудови.

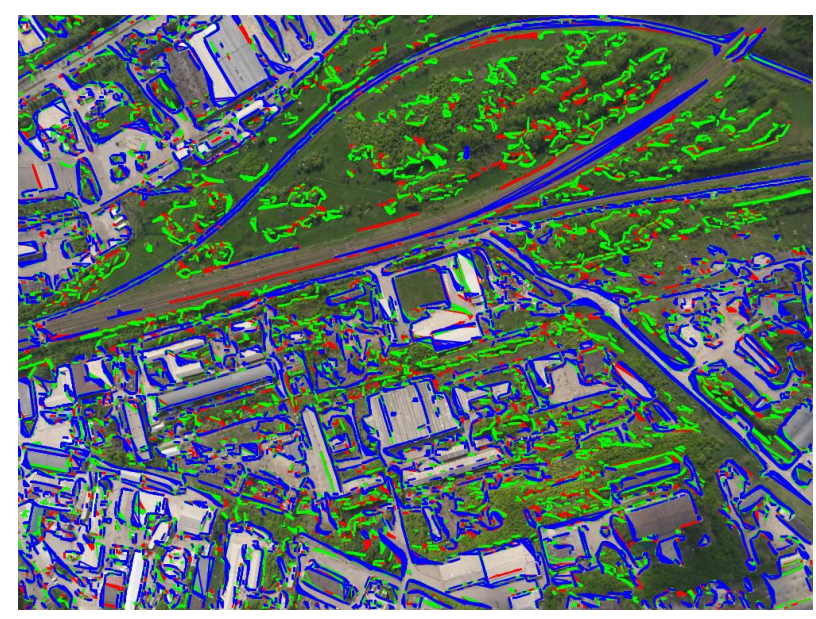

Рис. 7. Результат накладення рис. 6 на вихідне зображення (рис. 4) з метою виділення об'єктів міської забудови

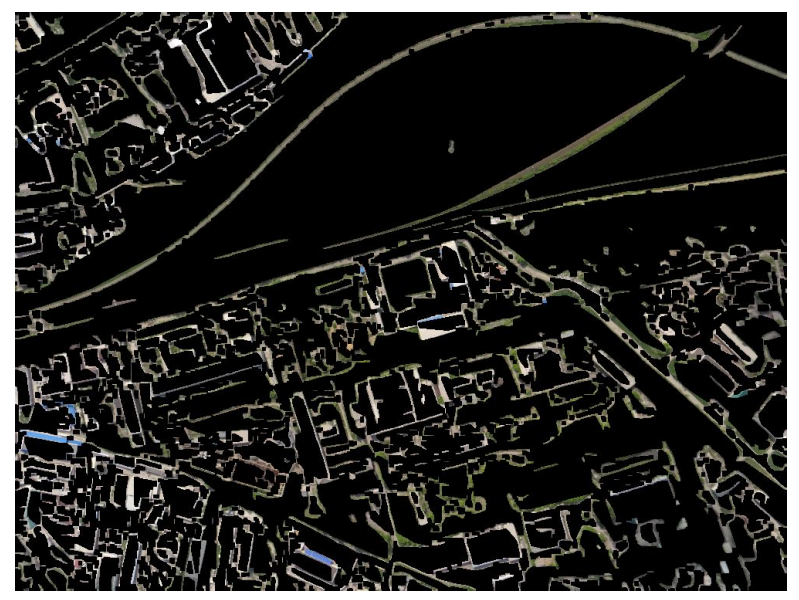

Рис. 8. Виділені об’єкти міської забудови

\section{Висновки і напрямки подальших досліджень}

Візуальна якість дозволяє виділити об'єкти міської забудови на обробленому зображенні. Отже, отримані результати показують, що запропонований метод може бути використано для знаходження об'єктів міської забудови. Для покращення роботи методу $є$ перспективним використання багатомасштабного методу обробки зображень.

\section{СПИСОК ЛІТЕРАТУРИ}

1. Гольц, Томас. Georgia Diary: A Chronicle of War and Political Chaos in the Post-Soviet Caucasus. — Sharpe, 2006. $262 \mathrm{c}$.

2. Орхан Джемаль. Война. Хроника пяти дней. - М.: Амфора, 2008. - 224 с.

3. Кузнецов Д. В. Иракский кризис. Очерк событий. Документы и материалы: Учебное пособие. - Благовещенск: Издво БГПУ, 2006. - 259 с.

4. Соломоненко Ю.С. Перетворення Хоха як метод виділення контурів об'єктів на оптико-електронних зображеннях / Ю.С.Соломоненко, Г.В.Худов, Р.В.Дзюбчук // Проблеми створення, випробування, застосування та експлуатації складних інформаційних систем: Збірник наукових праць. - Ж.: ЖВІ ДУТ, 2014. - Вип. 9. - С. 98-104.

5. Ruban, I. Redistribution of base stations load in mobile communication networks / I. Ruban, H. Kuchuk, A. Kovalenko // Innovative technologies and scientific solutions for industries. $-2017 . \quad-$ No 1 (1) - P. 75-81. DOI : https://doi.org/10.30837/2522-9818.2017.1.075. 
6. Коваленко А. А. Использование временных шкал при аппроксимации длины очередей компьютерных сетей / А. А. Коваленко, Г. А. Кучук, И. В. Рубан // Современное состояние научных исследований и технологий в промышленности. - 2018. - № 2(4). - C. 12-18. - DOI: https://doi.org/10.30837/2522-9818.2018.4.012.

7. Коваленко А. А. Сучасний стан та тенденцій розвитку комп'ютерних систем об'єктів критичного застосування / А. А. Коваленко, Г. А. Кучук // Системи управління, навігації та зв'язку: Збірник наукових праць - Полтава : ПНТУ, 2018. - № 1 (47). - C. 110-113. - DOI : https://doi.org/10.26906/SUNZ.2018.1.110.

8. Абрамов Н. С., Хачумов В. М. Распознавание на основе инвариантных моментов // Вестник РУДН. 2014. №2. C.142-149.

9. Кудрина М. А. Использование преобразования Хафа для обнаружения прямых линий и окружностей на изображении / М. А. Кудрина // Известия Самарского научного центра Российской академии наук. - 2014. - Т. 16, № 4(2). - С. 476-481.

10. Canny J. F. A Computational Approach to Edge Detection / J. F. Canny // IEEE Transactions on Pattern Analysis and Machine Intelligence. — 1986. — № 8. — P. 679-698.

Рецензент: д-р техн. наук, проф. О. В. Барабаш, Державний університет телекомунікацій, Київ Received (Надійшла) 19.11.2018

Accepted for publication (Прийнята до друку) 05.12.2018

\section{Метод выделения объектов городской застройки на изображениях бортовых систем оптико-электронного наблюдения с использованием преобразования Хафа \\ Г. В. Худов, А. Н. Маковейчук, И. А. Хижняк, Ю. С. Соломоненко, И. Ю. Юзова}

Предметом изучения в статье является метод выделения объектов городской застройки на изображениях бортовых систем оптико-электронного наблюдения. Целью является разработка метода выделения объектов городской застройки на изображениях бортовых систем оптико-электронного наблюдения. Задачи: обоснование необходимости выделения объектов городской застройки на изображениях бортовых систем оптико-электронного наблюдения; изложения сущности метода выделения объектов городской застройки на изображениях бортовых систем оптикоэлектронного наблюдения; визуальная оценка качества выделения объектов городской застройки на изображениях бортовых систем оптико-электронного наблюдения. Используемые методы: методы теории вероятности, математической статистики, методы оптимизации, математического моделирования и цифровой обработки изображений. Получены такие результаты. Установлено, что актуальным является вопрос выделения на изображениях бортовых систем оптико-электронного наблюдения географического ландшафта, зданий, культурных центров и критических элементов инфраструктуры, типа предприятий, транспортных систем и других принципиальных застроек. Установлено, что объекты городской застройки (мосты, дороги, дома и т.д.) достаточно контрастные и содержат много прямых линий. Выделение объектов городской застройки рассматривается как двухэтапный метод, а именно, применение некоторого детектора границ и применения непосредственно преобразования Хафа. На первом этапе производится выделение границ, на втором - выделение прямых линий. В качестве детектора границ предложено использование детектора границ Канни. Выводы. Установлено, что визуальное качество позволяет выделить объекты городской застройки на обработанном изображении, а предложенный метод может быть использован для нахождения объектов городской застройки. Направлением дальнейших исследований является использование многомасштабного метода обработки изображений.

Ключевые слова: объекты городской застройки, оптико-электронное изображение, бортовая система наблюдения, преобразование Хафа, детектор границ Канни, визуальная оценка качества, цветовое пространство.

\section{Method for determining objects of urban development on images of onboard systems of optical-electronic observation using transformation of Hafa \\ H. Khudov, O. Makoveichuk, I. Khizhnyak, Y. Solomonenko, I. Yuzova}

The subject matter of the article is a method for determining the objects of urban development on the images of onboard systems of optical-electronic surveillance. The goal is to develop a method for determining the objects of urban development on images of onboard systems of optical-electronic surveillance. The tasks are: substantiation of the need to identify urban buildings on images of onboard systems of optical-electronic surveillance; the presentation of the essence of the method of identifying objects of urban development on the images of onboard systems of optical-electronic surveillance; visual assessment of the quality of the selection of urban buildings on the images of onboard systems of optical-electronic surveillance. The methods used are: methods of probability theory, mathematical statistics, optimization methods, mathematical modeling and digital image processing. Such results are obtained. It has been established that the issue of identifying the geographical landscape, buildings, cultural centers and critical elements of the infrastructure, such as enterprises, transport systems and other fundamental developments on the images of the onboard systems of optical-electronic observation, is topical. It is established that the objects of urban development (bridges, roads, houses, etc.) are quite contrasting and contain many straight lines. The selection of objects of urban development is considered as a two-step method, namely, the use of a certain border detector and the application of the Hough transform. At the first stage, the selection of boundaries is made, at the second - the selection of straight lines. As a boundary detector, the use of a Canny boundary detector has been proposed. Conclusions. It was established that the visual quality allows to reveal objects of urban development on the processed image, and the proposed method can be used to find objects of urban development. The direction of further research is the use of a multiscale image processing method.

Keywords: objects of urban development, optoelectronic image, on-board observation system, Hough transform, Canny border detector, visual quality assessment, color space. 